ISSN: 2594-4827

\title{
AS ESTRATÉGIAS DE ENSINAGEM NO ENSINO MÉDIO INTEGRADO À EDUCAÇÃO PROFISSIONAL: UMA ANÁLISE DOS PLANOS DE ENSINO ${ }^{1}$
}

\author{
Nieysila Simara da Silva Castro Borges ${ }^{2}$ \\ Rilda Simone Maia da Silva ${ }^{3}$ \\ Deuzilene Marques Salazar ${ }^{4}$ \\ Soraya Farias Aquino 5
}

\section{RESUMO}

As estratégias utilizadas no processo de ensinagem tem como intuito a consecução e o desenvolvimento dos objetivos da prática educativa. Este artigo tem por objetivo analisar as estratégias de ensinagem dos professores em um contexto de Educação Profissional e Tecnológica, mais especificamente de um curso técnico na forma integrada ao ensino médio. Para alcançar este fim, partimos da questão problematizadora: quais as principais estratégias de ensinagem nos planos de ensino de um curso técnico integrado ao ensino médio? Para consecução desse objetivo fez-se a análise dos planos de ensino de um curso técnico na forma integrada ao ensino médio. $\mathrm{O}$ estudo indicou que as estratégias de ensinagem delineadas nos planos de ensino trazem operações de pensamento que apontam para o desenvolvimento do estudante como protagonista de sua aprendizagem.

Palavras-chave: Ensino médio integrado; Estratégias de ensinagem; Planos de ensino.

\section{THE TEACHING STRATEGIES IN MIDDLE SCHOOL INTEGRATED TO PROFESSIONAL EDUCATION: AN ANALYSIS OF THE TEACHING PLANS}

\section{ABSTRACT}

The strategies used in the teaching process are intended to achieve and develop the objectives of the educational practice. This article aims to analyze the teaching strategies, of teachers, in a context of Technological and Professional Education, more

\footnotetext{
${ }^{1}$ Uma versão preliminar desse texto foi apresentada no I Simpósio Amazônico em Educação Profissional e Tecnológica, promovido pelo ProfEPT/IFAM/CMC, realizado em Manaus, Amazonas, nos dias 28 a 29/11/2018.

2 Estudante do Mestrado Profissional em Educação Profissional e Tecnológica, Instituto Federal de Educação, Ciência e Tecnologia do Amazonas, nieysila.castro@ifma.edu.br

3 Estudante do Mestrado Profissional em Educação Profissional e Tecnológica, Instituto Federal de Educação, Ciência e Tecnologia do Amazonas, rildasimone@ gmail.com

${ }^{4}$ Doutora em Educação. Professora do Mestrado Profissional em Educação Profissional e Tecnológica, Instituto Federal de Educação, Ciência e Tecnologia do Amazonas, deuzilenemarques@gmail.com.

5 Doutora em Sociedade e Cultura na Amazônia. Professora do Mestrado Profissional em Educação Profissional e Tecnológica, Instituto Federal de Educação, Ciência e Tecnologia do Amazonas, soraya.aquino@ifam.edu.br
} 
specifically, of a technical course in the form integrated to high school. To achieve this aim, we start with the problematizing question: what are the main teaching strategies in the teaching plans of a technical course integrated to secondary education? In order, to achieve this objective, the analysis of the teaching plans of a technical course in the form integrated to secondary education was carried out. The study indicated that the teaching strategies delineated in the plans of teaching bring operations of thought that point to the development of the student as protagonist of their learning.

Keywords: Integrated high school; Teaching strategies; Teaching plans.

\section{INTRODUÇÃO}

A estratégia do processo de ensinagem se constitui na mediação do conhecimento histórico acumulado socialmente, ou seja, objetiva a apropriação do conhecimento sistematizado. A definição das estratégias de ensinagem pelo professor representa uma intencionalidade educativa e, por sua vez, indica a sua postura epistemológica de ensino e de aprendizagem.

Ensinagem é um termo utilizado por Anastasiou e Alves (2004) para indicar uma prática social complexa efetivada entre os sujeitos, professor e aluno, englobando tanto a ação de ensinar quanto a de apreender, em processo contratual, de parceria deliberada e consciente para o enfrentamento na construção do conhecimento escolar, resultante de ações efetivadas na, e fora, da sala de aula.

Assim, objetivamos analisar as estratégias de ensinagem de um contexto de Educação Profissional e Tecnológica, mas especificamente de um curso técnico na forma integrada ao ensino médio. Partimos da seguinte questão problematizadora: quais as principais estratégias de ensinagem dos planos de curso na educação profissional técnica de nível médio? Para a consecução desse estudo fez-se a análise de doze (12) planos de ensino de um curso técnico na forma integrada ao ensino médio.

O texto se desenvolve em três partes, além da introdução e das considerações finais: na primeira, discorremos sobre o Ensino Médio Integrado à Educação Profissional; na segunda, tratamos das estratégias de ensinagem e, por fim, na terceira, discorremos sobre as operações de pensamentos utilizadas nas principais estratégias de ensinagem nos planos de ensino de um curso técnico.

Esperamos que o estudo agregue à discussão perspectivas de materialização do currículo integrado, evidenciando a importância da definição de estratégias de 
ensinagem que ressignifiquem o ato de ensinar e aprender, bem como o rompimento das formas mecanizadas de transmissão do saber.

\section{METODOLOGIA}

Para este estudo optou-se por uma abordagem qualitativapartindo do pressuposto de que se constitui como a mais adequada para essa finalidade, uma vez que se configura como pesquisa no campo social e educacional, portanto, rica em contradições sociais. Associa-se a essa compreensão, os estudos de Chizzotti (2017, p.96) quando argumenta que as ciências humanas e sociais:

[...] se empenharam em mostrar a complexidade e as contradições de fenômenos singulares, a imprevisibilidade e a originalidade criadora das relações interpessoais e sociais (...) valorizaram aspectos qualitativos dos fenômenos, expuseram a complexidade da vida humana (...) se dedicaram a análise dos significados que os indivíduos dão às suas ações, no meio ecológico em que constroem as suas vidas e suas relações.

Trata-se de pesquisa bibliográfica e documental. De acordo com Chizzotti (2017, p.26) a pesquisa documental é indispensável para se conhecer o que já foi bem investigado, o que falta investigar, os problemas ainda controversos, obscuros, inadequadamente estudados ou que ainda persistem, reclamando novos estudos. Nesse intuito, buscou-se, a partir da análise de planos de ensino, identificar as principais estratégias de ensinagem adotadas pelos professores da base profissional de uma instituição de ensino no contexto da EPT, mais especificamente de um curso técnico integrado ao ensino médio.

Apresentou-se a hipótese de que as estratégias de ensinagem adotadas pelos professores trazem operações de pensamento que apontam para o desenvolvimento do estudante como protagonista de sua aprendizagem, portanto, se aproximam de uma abordagem metodológica crítica e dialética de construção do conhecimento. Para isso, foram selecionados para análise os planos de ensino referente às disciplinas do eixo especifico do curso.

Os dados foram coletados através da análise documental de 12 (doze) planos de ensino. Após identificar as principais estratégias de ensinagem adotada pelos docentes elaborou-se dois quadros analíticos para subsidiar o trabalho de interpretação dos dados. 
Os quadros apresentam a identificação, as descrições e operações de pensamento das principais estratégias de ensinagem verificadas nos planos de cursos. A organização dos dados foi realizada com base nas informações do plano de ensino associada aos estudos de Anastasiou e Alves (2009).

\section{O ENSINO MÉDIO INTEGRADO À EDUCAÇÃO PROFISSIONAL: OS SENTIDOS DA INTEGRAÇÃO}

O ensino médio integrado passou a ser implementado no Brasil a partir do advento do decreto $\mathrm{n}^{\circ}$ 5.154/04 cuja finalidade é regulamentar os artigos da lei de diretrizes e bases da educação nacional que tratam da educação profissional e tecnológica ( $\$ 2^{\circ}$ do artigo 36 e os artigos 39 a 41). A promulgação desse decreto é o resultado de uma luta histórica por um ideal de educação igualitária e emancipatória, concebida como uma formação integral e integrada, onde o trabalho seja compreendido como um princípio educativo. Esse ideal de educação está ligado a um projeto de sociedade que almeja a superação das desigualdades de classes e a garantia de condições dignas ao trabalhador para produzir a sua existência.

O ensino médio integrado surge então nesse contexto de luta, resistência e esperança. Por essa razão, estudiosos e educadores da área tem se debruçado na busca por um caminho que garanta a real integração entre o ensino médio e a educação profissional e tecnológica, cujas práticas educativas sejam sustentadas por uma concepção de formação humana integral.

Compreender a formação humana integral pressupõe considerar o trabalho como princípio educativo, que incorpora a dimensão intelectual ao trabalho produtivo e busca a formação de pessoas capazes de atuar como dirigentes e cidadãos. Essa concepção expressa uma formação omnilateral dos sujeitos, com base na integração do trabalho, da ciência e da cultura como dimensões que fazem parte da vida no processo educativo (BRASIL, 2007).

Essas dimensões precisam estar inteiramente integradas para consolidação de uma educação que propicie a formação humana integral. Essa educação possui dois pilares fundamentais que sustentam uma educação emancipadora: a escola unitária e a educação politécnica. Ramos (2005) explica que a concepção de escola unitária revela 
o princípio da educação como direito de todos, onde todas as pessoas têm acesso ao conhecimento e à cultura construídos pela humanidade, e podem escolher a produção de sua existência, por meio do trabalho. A educação politécnica propicia o acesso à ciência, à cultura e ao trabalho por meio da relação entre a educação básica e profissional.

Nessa concepção não existe separação entre trabalho manual e trabalho intelectual, eles constituem uma totalidade indissociável. Por essa premissa não se reconhece a possibilidade de existir trabalho manual puro e trabalho intelectual puro (SAVIANI, 2003), ou seja, todo trabalho manual envolve aspectos intelectuais e todo trabalho intelectual pressupõe atividade manual.

Vemos, então, que uma educação profissional e tecnológica com base na formação humana integral, cujo alicerce é a escola unitária e a politecnia, tendo como eixo estruturante o trabalho como princípio educativo pode propiciar ao estudante condições de conhecer a sua história e aumentar a chance de intervir nela, mudando os rumos.Pode formar o trabalhador com conhecimentos históricos e científicos da produção, de maneira que ele consiga compreender e superar a lógica do capital.

Compreendemos que ampliar a discussão sobre a relação entre educação e trabalho sob a ótica da ensinagem no ensino médio integrado na perspectiva da formação humana integral é propiciar meios para que a comunidade entenda as situações postas e busque formas de resistência. Nesse sentido, Ramos (2017) atribui quatro sentidos para a integração entre a educação básica e a educação profissional: filosófico, ético-político, epistemológico e pedagógico.

O sentido filosófico expressa a concepção de mundo, de homem, de sociedade e de educação que deve direcionar as relações e práticas pedagógicas efetivadas na escola. Compreende o ser humano como produto das relações histórico-sociais e da própria realidade. (RAMOS, 2017). Esse sentido possibilita a formação humana integral dos sujeitos pois implica a integração dos aspectos fundamentais da vida que estruturam a prática social: trabalho, ciência e cultura, conforme já elucidamos nos parágrafos anteriores.

O sentido ético-político remete a indissociabilidade entre a educação profissional e a educação básica. A educação básica, especialmente no nível médio, é a etapa em que os estudantes começam a inserção no mundo do trabalho; é também o nível em que a 
relação entre o conhecimento científico e as práticas produtivas fica mais evidente. A educação profissional e tecnológica, quando integrada à educação básica, advém de uma concepção de formação que busca a apropriação pelos estudantes dos conhecimentos que estruturam sua inserção digna na vida produtiva.

O sentido epistemológico trata da integração dos conhecimentos gerais e específicos como totalidade no campo curricular. Essa é uma discussão necessária no contexto da integração, pois desmistifica a hierarquização dos conhecimentos no currículo escolar. Destacamos as seguintes proposições: o conhecimento denominado específico - de caráter profissionalizante, se for desvinculado das teorias gerais do campo científico não terá utilidade em contextos distintos do que foi aprendido (RAMOS, 2009), portanto, será um conhecimento ocioso; e o conhecimento dito de formação geral - constituído pelos componentes curriculares: Português, Matemática, Física, História, entre outros - só adquire sentido quando reconhecido a partir do contexto real, na perspectiva do potencial produtivo. (RAMOS, 2017). Nestes termos, evidencia-se que no currículo integrado, mesmo que os componentes curriculares sejam identificados como de formação geral ou específica, eles são organizados visando a corresponder à totalidade como síntese de múltiplas determinações. (RAMOS, 2017).

O sentido pedagógico da integração implica nas formas de selecionar, organizar e ensinar os conhecimentos destinados à formação pretendida. Ramos (2017) propõe a seleção integrada de conteúdos de ensino a partir da problematização dos processos produtivos em suas diversas dimensões: tecnológica, econômica, histórica, ambiental, social, cultural, dentre outras. A autora esclarece que no decorrer dessa seleção integrada pode haver necessidade de complementação tanto para a formação geral, quanto da específica.

Para tanto, seria necessário identificar relações dos conteúdos selecionados com outros do mesmo campo, num processo disciplinar e, identificar relações com conteúdos de campos distintos, numa perspectiva interdisciplinar. Espera-se que a proposta curricular revele uma unidade teórica e metodológica.

\section{ESTRATÉGIAS DE ENSINAGEM COMO INDICADORES EPISTEMOLÓGICOS DO TRABALHO DOCENTE}


É no contexto da Educação Profissional e Tecnológica, dentro da perspectiva de currículo integrado, que situamos o processo de ensinagem proposto por Anastasiou e Alves (2004) como um caminho para a concretização da formação humana integral no ensino médio integrado e superação da concepção tecnicista.

Trata-se de uma ação de ensino da qual resulta a aprendizagem do estudante, superando o simples dizer do conteúdo por parte do professor, pois é sabido que na aula tradicional, que se encerra numa simples exposição de tópicos, somente há garantia da citada exposição, e nada se pode afirmar acerca da apreensão do conteúdo pelo aluno. Nessa superação da exposição tradicional, como única forma de explicitar os conteúdos, é que se inserem as estratégias de ensinagem (ANASTASIOU; ALVES, 2004, p.79)

As estratégias de ensinagem são consideradas como ferramentas de trabalho que subsidiam a incursão de um movimento dialético na apreensão do conhecimento e da realidade. Na dialética o pensamento passa necessariamente por uma afirmação ou tese inicial, a construção de sua contradição, ou antítese da mesma, para se chegar a uma síntese. Anastasiou e Alves (2004) pontuam que aos momentos de tese, antítese e síntese, pode se associar os momentos processuais do pensamento do aluno. Isso ocorre quando o aluno ao se confrontar com um tópico de estudo, o professor pode esperar que ele apresente apenas uma visão inicial, não elaborada e sincrética desse objeto.

Após vivenciar processos sistemáticos de análise sobre o objeto, o aluno passa a reconstruir essa visão inicial, sendo superada por uma nova visão, ou seja, a síntese. Essa síntese é sempre provisória, apesar de ser qualitativamente superior a ideia inicial, pois o pensamento está em constante movimento.

Vasconcelos (1992) traz grandes contribuições sobre o método dialético de ensino em contraponto com a metodologia expositiva, de viés tradicional. Para o autor, na metodologia expositiva o aluno corre um grande risco de não aprendizagem uma vez que existe um baixo nível de interação, além de se constituir como um problema político pois objetiva a formação de um homem passivo, sem criticidade e o papel que desempenha como fator de seleção social (VASCONCELOS, 1992).

Por outro lado, a metodologia dialética baseia-se em outra concepção de homem e de conhecimento, entendendo o homem como um ser ativo e de relações. O conhecimento é construído pelo sujeito na sua relação com os outros e com o mundo. 
Desse modo, o conteúdo que o professor apresenta precisa ser trabalhado e reelaborado pelo aluno, para se constituir em conhecimento dele. Desse modo, uma metodologia dialética poderia ser expressa por meio de três dimensões no decorrer do trabalho pedagógico: a mobilização, a construção e a elaboração da síntese do conhecimento. (VASCONCELOS, 1992).

A mobilização supõe o interesse do sujeito em conhecer. Este interesse precisa ser provocado e visa possibilitar o vínculo significativo inicial entre o sujeito e o objeto. Nesse momento, o sujeito elabora as primeiras representações mentais do objeto a ser conhecido. Na construção, o sujeito deve construir o conhecimento através da elaboração de relações o mais completa possível. Quanto mais abrangentes e complexas forem as relações, melhor o sujeito estará conhecendo. E a elaboração da conclusão é a dimensão relativa à sistematização do conhecimento bem como a sua expressão. Essas três dimensões orientam o processo de construção do conhecimento, elas não seguem necessariamente uma sequência rígida, a sua real importância está em vivenciar todos esses momentos. (VASCONCELOS, 1992).

$\mathrm{Na}$ seção a seguir, iremos tratar das práticas pedagógicas que direcionam a atividade docente dentro de uma instituição de Educação Profissional e Tecnológica, identificando as principais estratégias de ensinagem utilizadas em sala de aula pelos professores do curso técnico na forma integrada ao ensino médio.

\section{AS ESTRATÉgIAS DE ENSINAGEM NOS PLANOS DE ENSINO DE UM CURSO TÉCNICO NA FORMA INTEGRADA AO ENSINO MÉDIO}

O planejamento de ensino deve ser compreendido como uma ação intencional que objetiva a intervenção pedagógica com vistas a potencializar o ensino assegurando a apropriação do conhecimento sistematizado socialmente. As estratégias de ensinagem constituem a instrumentalização dos objetivos educativos previstos para a aprendizagem.

Com intuito de identificar as principais estratégias de ensinagem dos professores da educação Profissional Técnica de Nível recorremos a análise de doze (12) planos de ensino de um técnico integrado ao ensino médio. A análise incidiu sobre as disciplinas do eixo de formação específica da matriz curricular do curso 
Constatamos que a estratégia de ensinagem mais frequente é a aula expositiva dialogada (75\%), seguido pelo estudo de caso (58\%), leituras dirigidas - estudo dirigido (58\%), debates -fóruns (41\%), aulas práticas e/ou visitas técnicas (25\%), trabalho em grupo (25\%), aula teórica com apresentação de slides (25\%), seminários (8\%), entrevistas (8\%), elaboração de um plano de negócio (8\%), trabalhos individuais (8\%), resolução de exercícios individual ou em grupo (8\%) e solução de problemas (8\%).'

O quadro 1 apresenta as descrições e operações de pensamento das principais estratégias de ensinagem identificadas nos planos de cursos.

A formação no curso técnico na forma integrada ao ensino médio deve ser orientada para a formação de um profissional com base técnica fundamentada, mas também e, principalmente, comprometido com a transformação da sociedade, com o respeito à cidadania, aos padrões éticos e ao meio ambiente, que possibilite a atuação política e social que contribua com o processo de produção de cultura e de conhecimento.

Segundo Anastasiou e Alves (2004), a aula expositiva dialogada é uma estratégia que objetiva a superação da postura tradicional da palestra docente. Para isso, o clima de cordialidade, parceria, respeito e troca são essenciais para mobilizar a participação dos estudantes para a apropriação do conhecimento. Conforme o objetivo pretendido, o professor encaminha as discussões para as categorias de historicidade, de totalidade, de criticidade, práxis, significação e os processos de continuidade e ruptura.

A formação no curso técnico na forma integrada ao ensino médio deve ser orientada para a formação de um profissional com base técnica fundamentada, mas também e, principalmente, comprometido com a transformação da sociedade, com o respeito à cidadania, aos padrões éticos e ao meio ambiente, que possibilite a atuação política e social que contribua com o processo de produção de cultura e de conhecimento. 
Quadro 1 - Descrições e operações de pensamento de estratégias de ensinagem

\begin{tabular}{|c|c|c|}
\hline $\begin{array}{l}\text { ESTRATÉGIA DE } \\
\text { ENSINAGEM }\end{array}$ & DESCRIÇÃO & $\begin{array}{c}\text { OPERAÇÕES DE } \\
\text { PENSAMENTO }\end{array}$ \\
\hline $\begin{array}{l}\text { Aula expositiva } \\
\text { dialogada }\end{array}$ & $\begin{array}{l}\text { O professor leva os estudantes a } \\
\text { questionarem, interpretarem e discutirem o } \\
\text { objeto de estudo, a partir do } \\
\text { reconhecimento e do confronto com a } \\
\text { realidade. Deve favorecer análise crítica, } \\
\text { resultando na produção de novos } \\
\text { conhecimentos. Propõe a superação da } \\
\text { passividade e imobilidade intelectual dos } \\
\text { estudantes. }\end{array}$ & $\begin{array}{l}\text { Obtenção e organização de dados } \\
\text { Interpretação } \\
\text { Crítica } \\
\text { Decisão } \\
\text { Comparação } \\
\text { Resumo }\end{array}$ \\
\hline Estudo dirigido & $\begin{array}{l}\text { No ato de estudar sob a orientação e } \\
\text { diretividade do professor, visando sanar } \\
\text { dificuldades específicas. } \\
\text { É preciso ter claro: o que, para quê, e do } \\
\text { como é preparada a sessão. }\end{array}$ & $\begin{array}{l}\text { Identificação } \\
\text { Obtenção e organização de dados } \\
\text { Busca de suposições } \\
\text { Aplicação de fatos e princípios a } \\
\text { novas situações. }\end{array}$ \\
\hline $\begin{array}{l}\text { Solução de } \\
\text { problemas }\end{array}$ & $\begin{array}{l}\text { No enfrentamento de uma situação nova } \\
\text { exigindo pensamento reflexivo, crítico e } \\
\text { criativo a partir dos dados expressos na } \\
\text { descrição do problema. }\end{array}$ & $\begin{array}{l}\text { Identificação } \\
\text { Obtenção e organização de dados } \\
\text { Planejamento } \\
\text { Imaginação } \\
\text { Elaboração de hipóteses } \\
\text { Interpretação } \\
\text { Decisão. }\end{array}$ \\
\hline Estudo de caso & $\begin{array}{l}\text { Na análise minuciosa e objetiva de uma } \\
\text { situação real que necessita ser investigada e } \\
\text { é desafiadora para os envolvidos. }\end{array}$ & $\begin{array}{l}\text { Análise } \\
\text { Interpretação, } \\
\text { Crítica } \\
\text { Levantamento de Hipóteses } \\
\text { Busca de suposições } \\
\text { Decisão } \\
\text { Resumo. } \\
\end{array}$ \\
\hline Fórum (debate) & $\begin{array}{l}\text { Num espaço, do tipo "Reunião" na qual } \\
\text { todos os membros do grupo têm a } \\
\text { oportunidade de participar do debate de um } \\
\text { tema ou problema determinado. } \\
\text { Pode ser utilizado após a apresentação } \\
\text { teatral, palestra, projeção de um filme, para } \\
\text { discutir um livro que tenha sido lido pelo } \\
\text { grupo, um problema ou fato histórico, um } \\
\text { artigo de jornal, uma visita ou uma } \\
\text { excursão. }\end{array}$ & $\begin{array}{l}\text { Busca de suposições } \\
\text { Hipóteses } \\
\text { Obtenção e organização de dados } \\
\text { Interpretação } \\
\text { Crítica } \\
\text { Resumo. }\end{array}$ \\
\hline
\end{tabular}

Fonte: Sistematizado pelas autoras com base em Anastasiou e Alves (2004).

Segundo Anastasiou e Alves (2004), a aula expositiva dialogada é uma estratégia que objetiva a superação da postura tradicional da palestra docente. Para isso, o clima de cordialidade, parceria, respeito e troca são essenciais para mobilizar a participação dos 
estudantes para a apropriação do conhecimento. Conforme o objetivo pretendido, o professor encaminha as discussões para as categorias de historicidade, de totalidade, de criticidade, práxis, significação e os processos de continuidade e ruptura.

Uma outra estratégia utilizada com frequência pelos professores é o estudo de caso que tem grande potencial de formação critica. Anastasiou e Alves (2004) destacam que nos estudos de caso o aluno é estimulado a organizar o pensamento para operações como: analise, interpretação, critica, levantamento de hipóteses, busca de suposições, decisão e resumo.

Gráfico 1 - Operações de pensamentos das estratégias de ensinagem mais frequentes

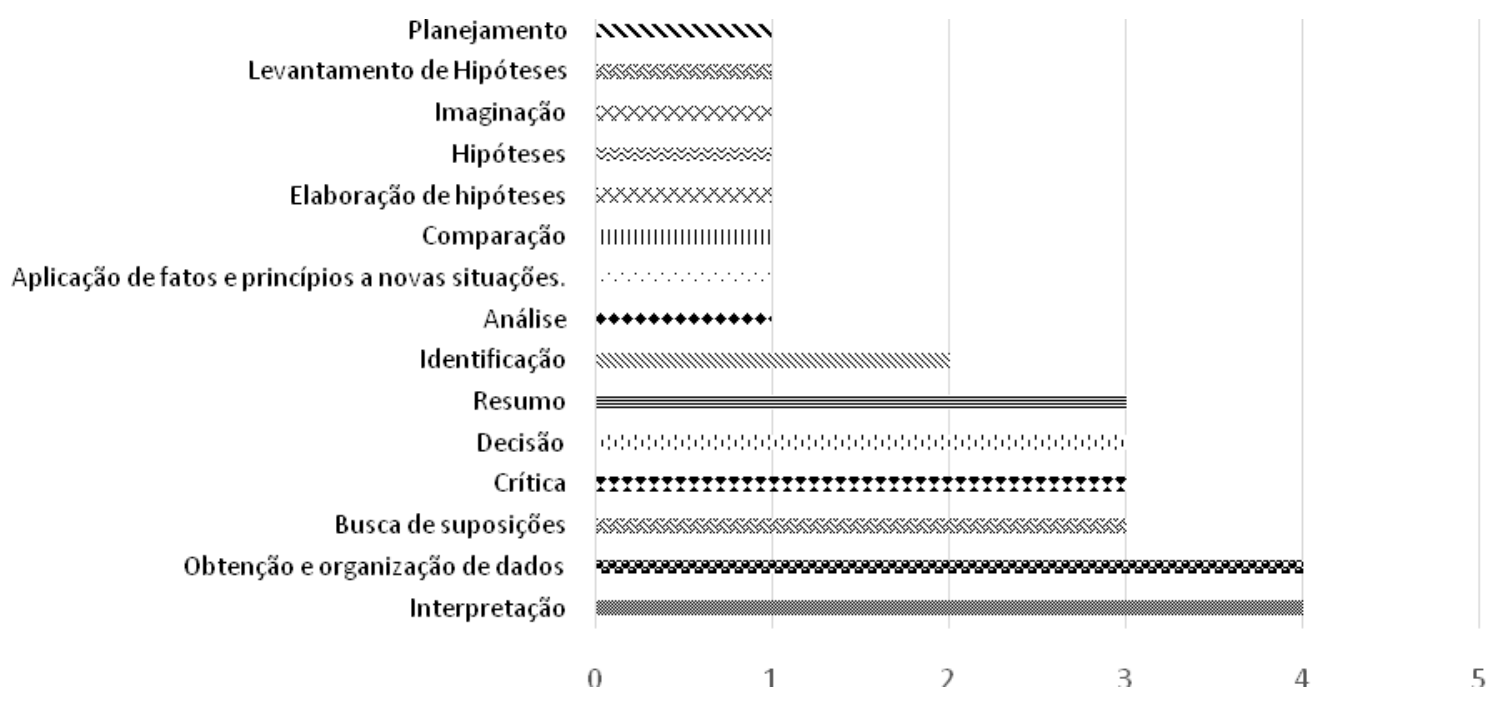

Fonte: As autoras com base nos planos de ensino das disciplinas, 2018.

As operações de pensamento desenvolvidas nas estratégias de ensinagem definidas nos planos de ensino indicam a interpretação, obtenção e organização de dados, busca de suposições, crítica, decisão e resumo. Estas operações sugerem uma postura ativa do estudante em relação ao seu aprendizado como também a ação docente quanto ao processo de mediação.

Para que o processo de ensinagem resulte em experiências que levem os estudantes relacionarem a teoria com a prática, tal como fala Saviani: 
O ensino médio envolverá, pois, o recurso às oficinas nas quais os alunos manipulam os processos práticos básicos da produção; mas não se trata de reproduzir na escola a especialização que ocorre no processo produtivo. O horizonte que deve nortear a organização do ensino médio é o de propiciar aos alunos o domínio dos fundamentos das técnicas diversificadas utilizadas na produção, e não o mero adestramento em técnicas produtivas. Não a formação de técnicos especializados, mas de politécnicos (SAVIANI, 2007, p.161).

Pensar em práticas pedagógicas dentro da Educação Profissional Tecnológica tendo como fundamento a politecnia, é pensar em múltiplas estratégias de ensino que propiciem aos estudantes relacionar teoria e prática e a experimentação do trabalho manual vinculado ao trabalho intelectual (SAVIANI, 2003), superando a pedagogia do saber-fazer.

\section{CONSIDERAÇÕES FINAIS}

O estudo ensejou reflexões sobre as estratégias de ensinagem que perpassam a prática docente dos professores de um curso técnico em administração na forma integrada ao ensino médio, buscando evidenciar se havia aproximação com os pressupostos da formação humana integral e com a pedagogia histórico-critica.

A partir do tratamento dos dados obtidos percebemos que a prática docente tem caminhado em direção de uma pedagogia crítica, buscando no método dialético a ressignificação do ato de ensinar e aprender, rompendo com as formas mecanizadas de transmissão do saber. O estudo revelou que a definição das estratégias de ensinagem, expressas nos planos de ensino dos professores, apontam para um processo de renovação do fazer pedagógico que busca a valorização do educando enquanto sujeito ativo de sua aprendizagem.

O ensino enquanto prática social está comprometido com um projeto de sociedade que se quer manter ou construir, nesse sentido a proposta pedagógica da Educação Profissional e Tecnológica tenciona romper com a histórica dualidade estrutural da educação brasileira que propunha formações diferenciadas para as elites e para a classe trabalhadora; e contribuir, dentro dos seus limites e possibilidades, para um novo modelo de sociedade. 
Este projeto de sociedade pressupõe uma educação comprometida com a emancipação dos sujeitos e com práticas sociais mais justas referenciada nos pressupostos da formação humana integral ou ominilateral. É o compromisso político com um projeto socialmente eficaz que deverá subsidiar a definição dos objetivos e estratégias de ensino dos cursos da Educação Profissional Técnica de Nível Médio.

Desse modo, defendemos a utilização das estratégias de ensinagem, dentro de uma abordagem crítica e dialética, como uma possibilidade de mobilização dos educandos na construção do conhecimento em sua totalidade. As estratégias de ensinagem apoiam-se nesse movimento dialético de construção do conhecimento e portanto, são um caminho viável e desafiador para a busca de uma educação emancipatória e superação das tendências liberais.

\section{AGRADECIMENTOS}

Aos mestrandos e professores do Mestrado Profissional em Educação Profissional e Tecnológica ProfEPT Campus Manaus Centro.

\section{REFERÊNCIAS}

ANASTASIOU, Léa das Graças Camargos; ALVES, Leonir Pessate. Estratégias de ensinagem. In: ANASTASIOU, Léa das Graças Camargos; ALVES, Leonir Pessate. (Orgs.). Processos de ensinagem na universidade: pressupostos para as estratégias de trabalho em aula. 3. ed. Joinville: Univille, 2004.

BRASIL. MEC. Educação Profissional Técnica de Nível Médio Integrada ao Ensino Médio. Documento base. Brasília, 2007. Disponível em: http://portal.mec.gov.br/setec/arquivos/pdf/documento_base.pdf Acesso em: 31 ago. 2017.

BRASIL, Ministério da Educação. Decreto $n^{\circ} 5.154$ de 23 de julho de 2004. Disponível em: http://www.planalto.gov.br/ccivil_03/_ato20042006/2004/decreto/d5154.htm. Acesso em: 09 de outubro de 2017.

CHIZZOTTI, Antonio. Pesquisa em ciências humanas e sociais. 12. Ed. São Paulo: Cortez, 2017.

LIBÂNEO, José Carlos. As teorias pedagógicas modernas revisitadas pelo debate contemporâneo na educação. In: LIBÂNEO, J. C.; SANTOS, A. (Orgs.). Educação na 
era do conhecimento em rede e transdisciplinaridade. Campinas: Alínea, 2005, p. 19- 63. Disponível em: < http://books.scielo.org>. Acesso em: 10 mai. 2018.

MOURA, Dante Henrique, FILHO, Domingos Leite Lima, SILVA, Mônica Ribeiro Silva. Politecnia e formação integrada: confrontos conceituais, projetos políticos e contradições históricas da educação brasileira. Revista Brasileira de Educação, v.20, n.63, out-dez 2015.

RAMOS, Marise Nogueira. Concepção do Ensino médio integrado. Disponível em:<http://forumeja.org.br/go/sites/forumeja.org.br.go/files/concepcao_do_ensino_med io_integrado5.pdf $>$. Acesso em: 20 set. 2017.

RAMOS, Marise Nogueira. Ensino Médio Integrado: lutas históricas e resistências em tempos de regressão. In: ARAÚJO, Adilson Cesar; SILVA, Cláudio Nei Nascimento da (orgs.). Ensino médio integrado no Brasil: fundamentos, práticas e desafios. Brasília: IFB, 2017. Disponível em https://www.ifpb.edu.br/joaopessoa/ensino/projeto-deatualizacao-dos-ppcs/documentos/materiais/snemi.pdf. Acesso em 15 jun. 2018.

SAVIANI, Demerval. O choque teórico da politecnia. Trabalho, Educação e Saúde, v. 1, p. 131-152, 2003. Disponível em: http:http://www.scielo.br/pdf/rbedu/v12n34/a11v1234.pdf. Acesso em: 31 Acesso em: 31 ago. 2017.

SAVIANI, Demerval. Pedagogia histórico-crítica: primeiras aproximações. 11. ed. Campinas, SP: Autores Associados, 2011.

VASCONCELLOS, Celso dos S. Metodologia dialética em sala de aula. Revista de Educação AEC, Brasília, n.83, abr. 1992. 